\title{
NOVEL ANIMAL WELL BEING CENTRIC ZOO LAYOUT MODEL AND ITS APPLICATION AT DHAULADHAR NATURE PARK
}

\author{
Bharat Kohli $1{ }^{\square}$, Vishal Thakur ${ }^{2}$ \\ ${ }^{1}$ Range Forest Officer ( Probationer ), Himachal Pradesh Forest Department, India \\ 2 Zoo Biologist, Dhauladhar Nature Park, Gopalpur, H.P., India
}
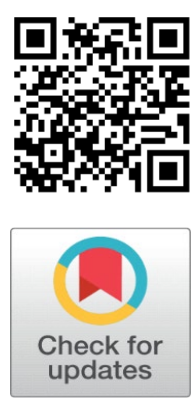

\section{ABSTRACT}

Zoological parks are the ex-situ conservation facilities to complement and strengthen the national efforts in conservation and strengthening the rich biodiversity of the country, particularly the fauna.[Zoos in India (2014)]. Scientific management and designing plays a key role for better upkeep and housing. While exploring this broad idea of scientific management, this paper focuses on establishment of enclosures for educative purpose and simultaneously keeping animal comfort on priority.

Keywords: Zoological Park, Himachal Pradesh, Architectural

Received 21 August 2021

Accepted 04 September 2021

Published 31 October 2021

\section{CorrespondingAuthor}

Bharat Kohli,

Bharatkohlihimachal@gmail.com

DOI 10.29121/ijetmr.v8.i10.2021.1030

Funding: This research received no specific grant from any funding agency in the public, commercial, or not-for-profit sectors.

Copyright: (C) 2021 The Author(s). This is an open access article distributed under the terms of the Creative Commons Attribution License, which permits unrestricted use, distribution, and reproduction in any medium, provided the original author and source are credited.

\section{INTRODUTION}

Dhauladhar Nature Park is a small category Zoological Park in Himachal Pradesh. It is expanded in 12.5ha area in district Kangra. It is clear that visitor circulation in Zoos have impact on the animals. The impact, negative or positive depends on the kind and intensity of flow of visitors and all this collectively dependent on designing of Zoo. Being the Zoo of small category, space constraint is a major factor that affects the working. Space constraint leads to overlapping of service and visitor path which in turn interrupts the management of the zoo. This may be solved with minor changes in the overall layout of the Zoo. This paper has been an attempt to address this problem.

The architectural design or the map of the zoo depicts the location and dimensions of the office, exhibit area, indoor holding area, visitor paths constitute together as the majot components of the Master (Layout) Plan of the Zoo. Central Zoo Authority is the competent authority to approve the Master (Layout) Plan of the recognized zoological parks recognized by CZA. We have deliberated and come up with a novel Master (Layout) Plan model that takes into account of 3 key parameters that one should keep in mind while designing the zoo: Animal welfare (i.e., making animal housing facility as comfortable as possible), seamless visitor experience and smooth working of zoo management personnel.

\section{ROUND REVOLUTION ZOO MASTER LAYOUT PLAN}

In this Master (Layout) Plan, all the works of the zoological park that are carried out by the zoo management staff are carried out using the service path which lies in the centre of the zoo and the visitors move from one end to 
other completing one complete round along the periphery of the zoo along the visitor path. Since the visitor completes the whole revolution of the zoo during the visit, we have termed it as "Round Revolution Design". The term 'Round' here refers to the complete one round of the zoo along the periphery. The word "Round" is not depicting the shape as the shape of the zoo boundary will depend on allotted space where the zoo needs to be built - The basic components of the round revolution design. This can be understood from the Figure 1.

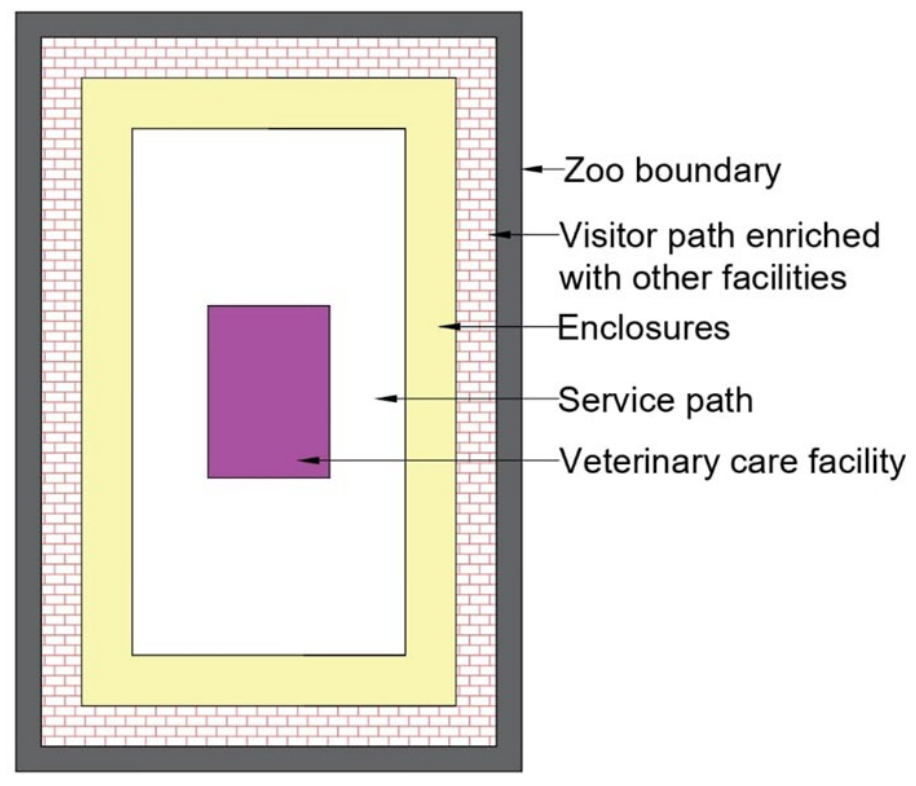

Figure 1 Layout of Zoo as per Round and Revolution Zoo Master (Layout) Plan design

There are key advantages of this novel Master (Layout) Plan design over the conventional Master (Layout) Plan design of this Zoo. These key advantages are:

- Animal well being centric: Since the enclosures are designed in such a way that rather than having several viewing sites available to visitiors all around exhibit, there is only one specific viewing area for visitors. This results in creating a situation where the animal in the enclosure will receive less stress from the presence of humans when compared to the enclosures where the viewing sites are more than one. Hence this layout design ensures relatively low psychological stress on the animals. Its more animal well being centric because it prioritizes the psychological well being of the animal which is an integral part of animal housing [Mental health (n.d.)].Also, animal keeper can keep an eye on their concerned animals without getting mixed with visitors. Also, preventing viewing from multiple directions can allow the animal to 
move at its own will. In multiple viewing situations, animal generally gets restricted at the centre of the exhibit as it avoids area near enclosure fencing. The situation gets severe where the size of exhibit is less than what it should be. In the Figure 2, the Image 2 is depicting the exhibit area in proposed layout model and Image 1 is depiciting the exhibit areas in the conventional zoo model.
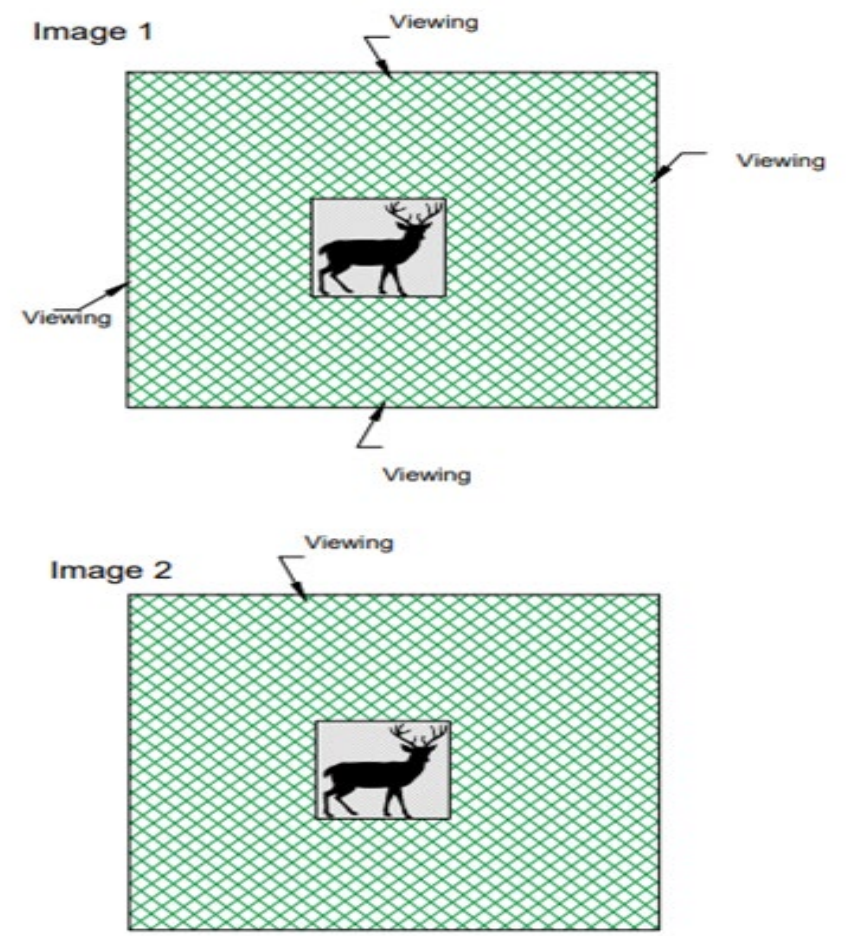

Figure 2 Difference in viewing after before (right) and after (left) the changes.

- Visitor friendly: In, this zoo layout model,the visitor does not need to spend time knowing the multiple directions in order to cover all the exhibits of the zoo. He or she can just begin from one point and cover the zoo at one go. This makes the experience of the visitor seamless and more hassle free and at the same time it also saves the time of the visitor. We assume and predict that total time to complete the zoo visit will be one of the key factor for a visitor while deciding the visit to the zoo in these modern fast paced world. This effect also transcends to the effect on the visitor footfall and hence the revenue generation of the zoo.

- Enables efficient zoo management: In this model, the enclosures, the night sheds and the zoo service paths have been designed in such a way that it enables the least overlap between the visitor path and the service path. This arrangement and design helps the zoo staff personnel to carry out their various duties like transportation, construction, emergency treatment and animal upkeep in a seamless manner which further translates into increased efficiency in zoo management. Also, separated service path and visitor path will ensure visitor safety 
- Better space utilization: When the enclosures in a novel Master (Layout) Plan are scattered, then it gives rise to spaces that could not be used for any purpose. But when the exhibits are stacked together then such non useful spaces are not created and instead a joint larger space is created. This can be seen in the pictorial representation in the Figure 3 where the areas in white are spaces available. If these grey boxes are stacked along the periphery of the given area, a larger space is created as seen in the Image 1 when compared to the multiple small spaces created in the Image 2 . Larger space provides more options to the architect in creating structures to the architect than the availability of small scattered spaces .

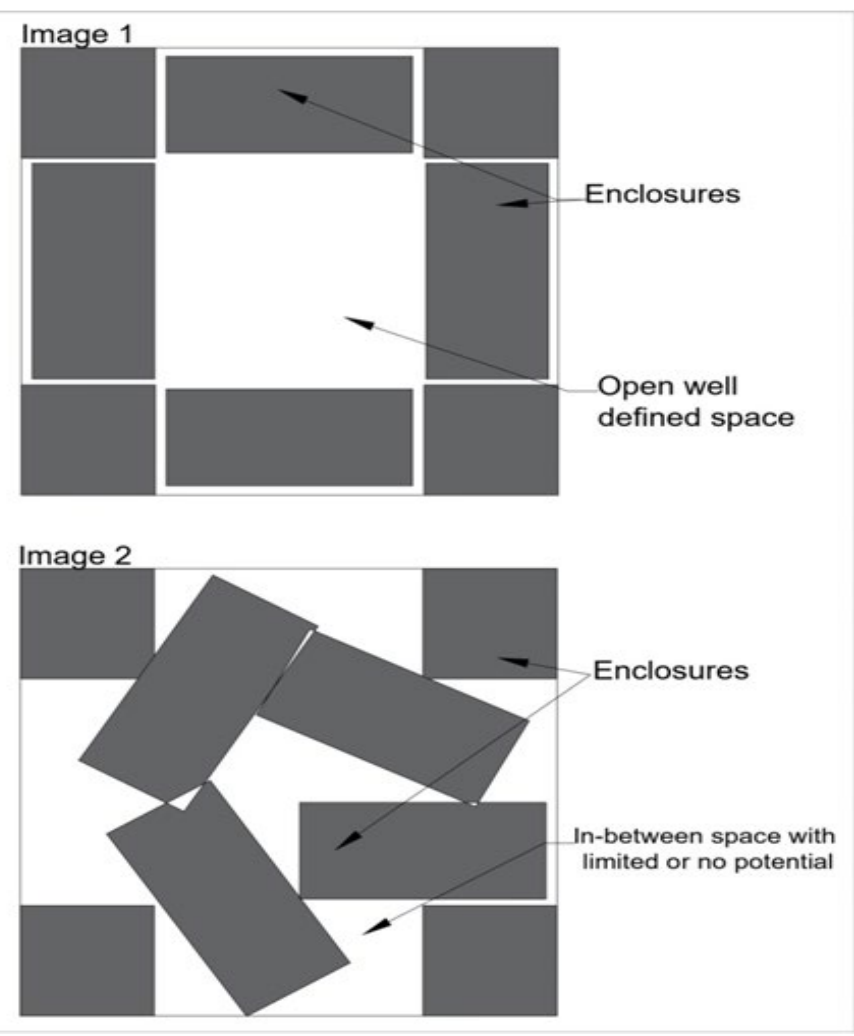

Figure 3 Depicting free space utilization.

\section{APPLICATION OF THIS MODEL AT DNP, GOPALPUR}

This novel design of novel Master (Layout) Plan has been applied in preparing the new Master (Layout) Plan at Dhauladhar Nature Park (a small zoological park), Himachal Pradesh Forest Department. This Master (Layout) Plan has been prepared and sent to the CZA for the approval. The image in Appendix-A shows the proposed master plan of the DNP Gopalpur zoological park. The line in red is the visitor path along the periphery of the DNP Gopalpur zoo. Other legends are also depicted in the digital image of the Master Plan prepared. 


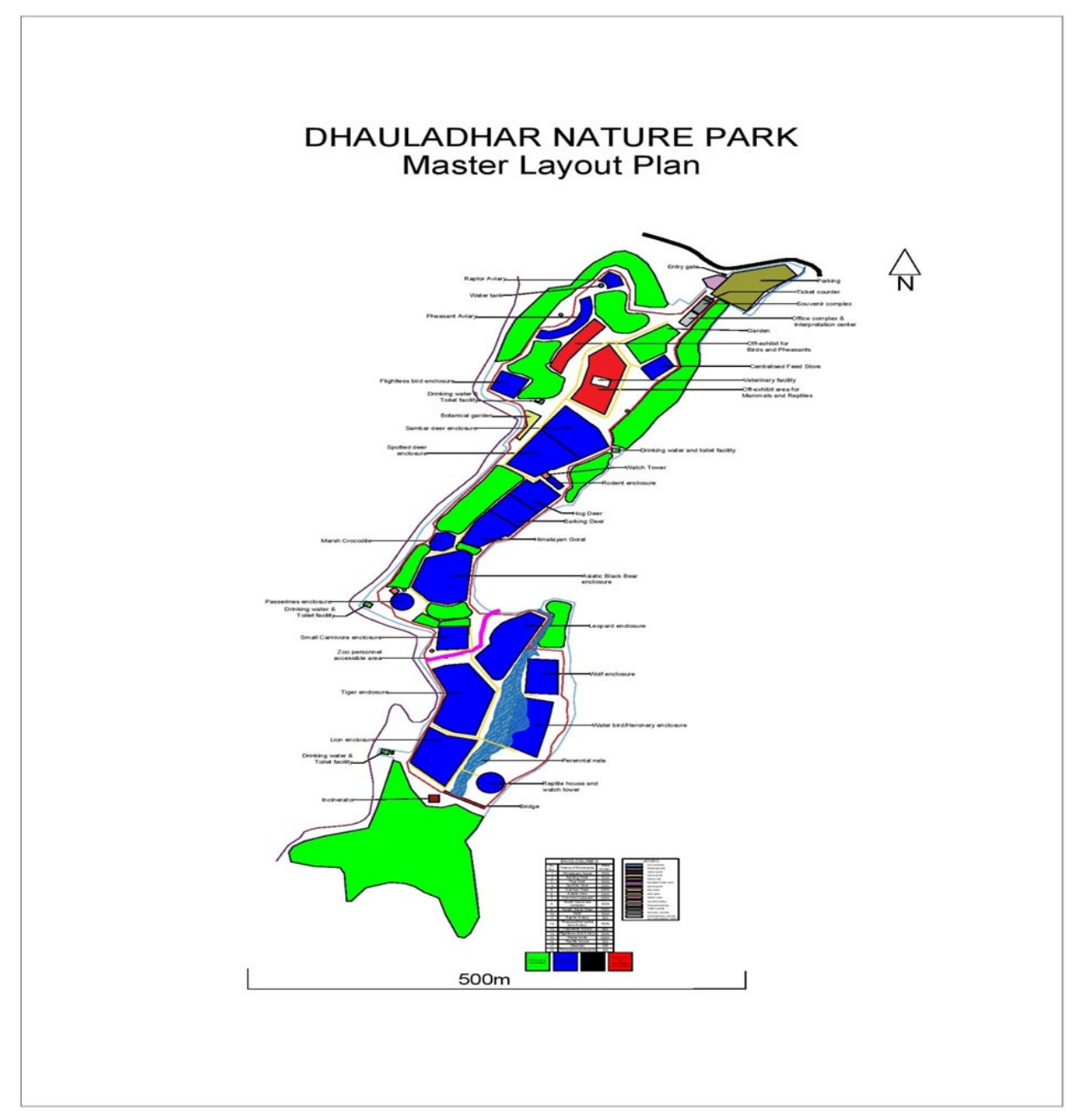

\section{ACKNOWLEDGEMENT}

We extend our gratitude and thank IFS Upasna Patial, Chief Conservator of Forests Willife (HQ Dharmashala) and IFS Rahul Rohane, DCF (Wildlife ), Hamirpur for their constant support and encourangement to explore our research ideas. In addition to this, we would like to thank Range office staff of DNP Gopalpur namely Sh. Surjeet Pathania ( Sr Fgd) , Sh. Reetu Patial ( Fgd) , Sh, Keval Krishan ( Fgd) and all other members of the staff for assisting us in carrying out our research work. We are thankful to our peers for their valuable suggestions as well. This would not have been possible without the ever supporting family members.

\section{REFERENCES}

Mental health (n.d.) and well beingin animals by David John Stepherdson ( Retd), Oregon zoo and Kathy Carlstead, Smithsonian institution.

Zoos in India (2014), Legislation, policy, guidelines and strategy . 